\title{
Ilha do Combú: um olhar sob as perspectivas conceituais do lazer e seus equipamentos
}

\section{Island of Combú: the local community according to the conceptual perspectives of leisure}

\author{
Arcanjo Miguel Garcia Maia, Jonathan Rodrigues Nunes, Silvia Helena Ribeiro Cruz
}

\begin{abstract}
RESUMO
Este trabalho tem como objetivo apresentar à sociedade a llha do Combú, área que pertence a Belém do Pará e suas diversas formas de ser trabalhado. A partir da questão conceitual do lazer, procurar-se-á, a partir do empreendimento particular de Dona Nena (Filha do Combú), e da festividade de Santo Antônio, fazer uma análise da diversidade que compõe as comunidades que residem na ilha, porém que não são trabalhadas da melhor forma possível, tomando como ponto de partida as teorias de diferentes autores referidos à lazer, tentando ressaltar a potencialidade que a ilha abrange sob a ampla perspectiva do aproveitamento de horas livres, tantos de turistas quanto de residentes do munícipio de Belém, sabido que ambos são relevantes para a perspectiva do estudo sobre lazer. O trabalho finalizará, portanto, tentando fazer um consenso entre as diferentes teóricas dos autores para com a classificação da llha em sua totalidade, sob a ótica destes estudos sobre o tema do lazer, suas motivações, e seus referidos equipamentos e suas classificações.
\end{abstract}

PALAVRAS-CHAVE: Ilha do Combú. Turismo. Lazer.

\section{ABSTRACT}

This paper has as objective approach the experience of Combú of the island community, place that belongs to Belém of the state of Pará, and due to the closeness to the capital while urban city has stronger relation with the visitation of eventual tourists whom haz the intection of approaching of green areas. Seeing that this flow produces na urbanizing impact in the area, the search proposed to approach the relation of the community with this new utility found in their place of everyday. Starting of the conceptual issue of leisure, it was made na analysis of yhe cultural and anthropological diversity that composes the families that reside in the island. And their relation with tourism. For such, it was made field visitis and open interview on the particular enterprise of Ms. Nena (Filha do Combú), and participant observation at the Santo Antônio de Piriquitatara festivity, one of the festivities that were occurring at the moment, seeking to pay attention to the frequencie and charactheristics on the recurrents tourists on site, as far as the perception of the local communnity to this touristic flow. The work endend trying to make na overview between the diferente theories of the authors to the island rating, both in relation to the use, as approaching the island as an equipment, and also in relation to the ends and motivations of tourists, always taking into account the percpetion of the local communnity.

KEYWORDS: Local Culture; Leisure; Riveirine Communities; Tourist Development. 


\section{Introdução}

Muito se fala sobre lazer, e sua direta relação na vida das pessoas. Os estudos brasileiros se voltaram para essa abrangente área a partir de 1970, sendo que na Europa começaram a partir de 1950 (MARCELLINO, 2006). A principal motivação para isso foi os direitos trabalhistas conquistados na década de 50 na Europa, onde os assalariados puderam ter direito à suas férias renumeradas e então aproveitarem alguma forma de lazer, deslocando-se para isso ou não. Essa nova dinâmica da sociedade onde o "digno" trabalha por horas, gerou várias teorias que colocavam em pauta a questão lazer x trabalho (DUMAZEDIER, 1974; MARCELLINO, 2006.). No Brasil, estas teorias se acentuaram a partir da década de70, mais pelo motivo da intensa urbanização ocorrida nas cidades no Brasil. (MARCELLINO, 2006.).

Estudos que se referem ao lazer fora da área urbana, no entanto, ainda são raros, pois muitos o tratam de forma indireta, usando-os como base para falar de cultura ou turismo de aventura, do qual se trata de uma proposta muito segmentada para serem fontes sólidas de um tema tão abrangente quanto o lazer, e que, por assim dizer, tem uma abrangência além dos equipamentos das grandes metrópoles do país.

É visível na atual comunidade acadêmica, o "esquecimento" das áreas verdes, no âmbito do lazer. O fato é que não se trata do assunto com frequência, ressaltando que estamos no contexto de um país como o Brasil que possui uma forte cultura ligada ao estilo de vida dentro das florestas. Por isso este trabalho se prende a área da llha do Combú (PA), e busca adequar esta Área de Proteção Ambiental (A.P.A.) às conceituações de estudiosos do lazer. Do que se trata uma área verde? Existem ramificações entre elas, no contexto do aproveitamento do lazer? São perguntas não necessariamente solvidas que ajudariam neste trabalho, e que por isso, se vê necessário levantar a discussão sobre este assunto, como proposta deste artigo.

\section{Metodologia}

Para o referido artigo foi-se necessário o uso de pesquisa bibliográfica e uma visita técnica para a obtenção de mais informações sobre um dos empreendimentos vigentes na ilha, a "fábrica" artesanal de chocolates "Filha do Combú". Além disso, foi feito o uso de observação participante, durante a festividade de Santo Antônio.

Nesta trajetória, procurará explanar-se o conceito do lazer, os interesses que o envolvem, e os conceitos de equipamentos de lazer, envolto dos pensamentos dos principais teóricos para a área do turismo, para então ser feita a relação desses conceitos na realidade seguinte aqui estudada, buscando adequar o contexto urbano da obra ao modo de vida ribeirinha sem que esta lhe perca a personalidade.

Sendo assim, foi realizada o levantamento bibliográfico das principais obras nacionais e internacionais, assim como o auxílio de artigos de temas relacionados, que é a tipologia de texto usado para essas pesquisas (SEVERINO, 1996). Usando como base este mesmo autor, as informações coletadas sobre o "Filha do Combú" e outros dados foram coletados da 
proprietária a partir de seu discurso livre, se caracterizando como uma entrevista não-diretiva (SEVERINO, 1996, p. 125).

A pesquisa, portanto, possui o caráter exploratório, que, explanando Gil (1999, p. 43), "visa proporcionar uma visão geral de um determinado fato, do tipo aproximativo; e possui ainda a finalidade básica de desenvolver, esclarecer e modificar conceitos e ideias para a formulação de abordagens posteriores". nas palavras de Lakatos e Marconi (2011, p. 86): "levar ao conhecimento do público intelectual ou especializado no assunto ideias novas, para sondagem de opiniões ou atualização de informes". Com base no Livro Metodologia do Trabalho Científico de Lakatos e Marconi, esta é uma pesquisa de tipo classificatório, pois como percebe-se ela vai buscar classificar e analisar objetivamente a ilha e a comunidade local dentro das questões do lazer. (LAKATOS E MARCONI, 2011, p.87).

\section{Lazer: histórico e conceito}

O lazer tem uma trajetória histórica bem interessante por sua mudança de percepção. Lafargue, na sua icônica obra "O Direito à Preguiça", alega que, na fase dos grandes filósofos gregos, o lazer era uma atividade aristocrática, onde apenas aqueles que "receberam a dádiva divina" eram capazes de desfrutar, e trabalhar seria até uma forma de se degradar em sua liberdade, enquanto aos "ignorantes", restava a atividade do labor. Além disso, os homens livres da antiguidade eram os mais livres, pois na época imperava a escravidão onde este grupo seleto praticava o ócio enquanto o resto da população era escravizado e obrigado a trabalhar, em condições precárias.

Porém, a partir da revolução industrial estabeleceu-se um novo estilo de vida, que mudou esta configuração. Antes o lazer era tido como algo livre e puramente ócio, ganha um formato do qual é "vendido", e para consumo, no pouco tempo disponível que o atual trabalhador dispõe na sua semana. O lazer é aquilo que também já é tão programado e automatizado pela massa, inibe a prática criativa e transformadora, se tornando um lazer passivo.

Dumazedier (1974) relata os conflitos envolvendo os conceitos na discussão teórica na Europa, onde de um lado um grupo de especialistas mais exigentes e rígidos, enquanto outros mais flexíveis. Por exemplo, certo grupo afirmava que o lazer poderia estar ligado ao trabalho, enquanto o outro afirmava que o lazer estava estritamente contido às horas de nãotrabalho. Discussões à parte, Dumazedier (1976, p.94) diz que o lazer é

"[...] um conjunto de ocupações às quais o indivíduo pode entregar-se de livre vontade, seja para repousar, seja para divertir-se, recrear-se e entreter-se ou ainda, para desenvolver sua informação ou formação desinteressada, sua participação social voluntária ou sua livre capacidade criadora após livrar-se ou desembaraçar-se das obrigações profissionais, familiares e sociais." 
No Brasil, Marcellino (2006) classifica lazer através do Tempo-Atitude, entre outras palavras o tempo disponível que você tem e a atitude livre. Marcellino (1997, p.31), dá seu parecer:

\begin{abstract}
"[...] o lazer é por mim entendido como a cultura compreendida no seu sentido mais amplo - vivenciada (praticada ou fruída) no tempo disponível. É fundamental, como traço definidor, o caráter "desinteressado" dessa vivência. Não se busca, pelo menos basicamente, outra recompensa além da satisfação provocada pela situação. $A$ disponibilidade de tempo significa possibilidade de opção pela atividade prática ou contemplativa".
\end{abstract}

Este item não pretende ser exaustivo e apresenta apenas os mais relevantes autores. A própria pedagogia e educação física reconhece o discurso do lazer, inclusive se apropriando dele para realizar seus estudos na área, mostrando a utilidade abrangente deste conceito e sua aplicabilidade.

\title{
A Ilha do Combú e suas múltiplas formas
}

A Ilha do Combú é uma Área de Proteção Ambiental (APA) através da lei no 6083 de 1997. Com $15 \mathrm{~km}$ de extensão, se localiza a aproximados $1,5 \mathrm{~km}$ ao sul de Belém e pertencente ao distrito de Outeiro, A ilha é onde comunidades ribeirinhas moram e vivem seu cotidiano de subsistência. Porém, é uma realidade que está aos poucos sendo mudada pela força do turismo, aonde pessoas fora de suas residências vão para um local considerado fora do seu cotidiano comum para novas experiências. Uma destas realidades mais impactadas foi a da família de Dona Nena, que ao fazer chocolate apenas voltado para o consumo familiar, como em outras famílias ribeirinhas, viu no seu quintal um negócio turístico deslanchar na sua frente, quando esta rotina de fazer o próprio alimento se tornou, à olhos estrangeiros, o "chocolate artesanal" de Dona Nena. Dentro da ilha, de fato este é o empreendimento que mais se volta para a recepção de turistas, ainda que de forma secundária, pois a principal tarefa do empreendimento está mais voltada à distribuição do chocolate para o mercado, nas palavras da dona do local.

A comunidade ribeirinha que reside no local se baseia na economia extrativista. Assim como dona Lena produz seu próprio chocolate para distribuição, há outros tipos de cultivo no local que consequentemente se tornam um negócio, uma forma de adicionar renda à família. Por mais que seja possível transformar o que há no quintal em negócio, porém ainda assim, num modo de vida simples, estas atividades ocuparão espaços de suporte na renda.

Vale destacar o fator de vantagem para o que faz desta localidade uma área de potencial turístico, que é a proximidade da área metropolitana de Belém, condicionando a este local uma facilidade no sentido geograficamente territorial, tanto para moradores da cidade, quanto sendo 
fator importantíssimo para um bom fluxo turístico. Apesar disso, também é importante reiterar que o local é uma área protegida, sugerindo que é mais conveniente que se pratique segmentos voltados para o ecoturismo.

\section{Ilha do Combú: o lazer e a comunidade}

A partir da análise de visão teórica sobre a Filha do Combú já se percebe a multiusualidade que envolve a ilha do Combú. Neste sentido, este também se configura como um equipamento não específico dentro desta linha teórica, pois a ilha é um local à parte da cidade de Belém, mais que funciona perfeitamente como um atrativo turístico, seja devido a proximidade da área metropolitana, seja devido a dinâmica cultural diferenciada.

Lembremos que há outros empreendimentos além do "Filha do Combú", apesar de serem voltados para o atendimento geral e não de um público turístico. Neste sentido entram principalmente os pequenos bares, que se caracterizam diferente exatamente por estarem a beira dos rios. Este é o meio em que as famílias também tiram seu sustento, podendo caracterizar, portanto, este espaço como um equipamento não-específico também.

Ora, o que define a vontade de um turista se deslocar para tal lugar é uma pergunta muito subjetiva. O que define o lazer são seus interesses, intrínseco nestes casos a vontade de conhecer uma nova cultura, de respirar o "ar puro" da floresta, de experimentar uma comida diferente. Isto, incluindo as festividades e outras diversas manifestações culturais poderiam caracterizar a ilha como um grande centro polivalente, porém ainda assim é a localidade e meio de subsistência e empreendimento de muitos ribeirinhos, pois para o cotidiano deste, "o rio é a sua rua".

Também foi ressaltada na entrevista a dificuldade de se trabalhar em conjunto na comunidade, devido certos empreendimentos ver o do estudo em questão mais como concorrência do que como algo para se trabalhar em parceria e beneficiar os dois lados. Isto acaba por contribuir mais para a fragmentação do local como área turística, funcionando assim apenas alguns pontos isolados, quando poderia haver um planejamento para se expandir, melhorar e qualificar as formas da comunidade local trabalhar seus negócios e a manutenção das suas tradições, podendo então tornar-se um lugar de ações constantes e podendo se efetivar como um "centro turístico" espontâneo, democrático, disponível para os visitantes e não voltado apenas para os turistas.

\section{Considerações finais}

Conclui-se, portanto, que a diversidade de abrangência da ilha da comunidade ribeirinha do Combú dispõe é para o lazer, a oportunidade de se ampliar suas variedades dentro da ilha, para além da Filha do Combú, e sim para a ilha em sua totalidade.

A ilha ainda é um mero equipamento de lazer não específico, porém por poder proporcionar diversos prazeres para seus turistas e diversas festividades para sua comunidade local, ainda se torna um espaço onde o lazer voltado ao cultural é predominante, onde o propósito é mergulhar no 
cotidiano ribeirinho, porém com um bom planejamento, a ilha poderia fornecer mais opções e equipamentos, abrangendo sua área de alcance dentro da teórica do lazer e que é portanto, importante para as compreensões das dinâmicas que envolvem individuo-cidade-espaço, dentro da busca do proveito do tempo disponível.

Este trabalho busca seu fim em despertar a reflexão sobre o que se vem falando ou não do lazer dentro das áreas verdes, principalmente dentro das APAS, que são lugares de proteção ambiental e merecem cuidado especial, e não tem como objetivo finalizar uma discussão teórica que está sempre buscando sua melhora, ao contrário, vem servir de gancho para novas ideias e novas discussões.

\section{Referências}

BATISTA, S.M.B. Cultura Ribeirinha: a vida cotidiana na ilha do Combú (PA). In: Jornada Internacional de Políticas Públicas, 2011. São Luís. Anais...São Luís, 2011.

BRUHNS, H.T. (Org.). Introdução aos estudos do lazer. Campinas: UNICAMP, 1997.

DUMAZEDIER, J. Sociologia empírica do lazer. São Paulo: Perspectiva, 1976.

DUMAZEDIER, J. Lazer e cultura popular - Debates. São Paulo: Perspectiva, 1976.

GIL, A.C. Métodos e técnicas de pesquisa social. São Paulo: Atlas, 1999.

LAKATOS, E.M.; MARCONI, M.A. Metodologia do Trabalho Científico. 7. Ed - São Paulo: Atlas, 2011.

MARCELLINO, N.C. Lazer e educação. Campinas: Papirus, 1990.

MARCELLINO, N.C. (Org.) Lazer e cultura. Campinas: Alínea, 2007.

MÜLLER, A. Espaços e equipamentos de lazer e recreação e as políticas públicas. Anais do XIV Encontro Nacional de Recreação e Lazer - ENAREL. 13 a 16 de Noviembre de 2002. UNISC. Santa Cruz do Sul - RS. Brasil.

ROCHA, D.C.; MATOS, L.S. Lazer da/na floresta: as práticas de lazer dos moradores e visitantes da ilha do combú em belém-pa-brasil. Revista Brasileira de Estudos do Lazer. Belo Horizonte, v.2, n.1, p.64-79, jan./abr. 2015.

SEVERINO, A.J. Metodologia do Trabalho Científico. 23 ed - São Paulo: Cortez, 2007. 
Arcanjo Miguel Garcia Maia: Universidade Federal do Pará, Belém, PA, Brasil.

E-mail: arcanjommaia@gmail.com

Link para o currículo Lattes: http://lattes.cnpq.br/3268879221665243

Jonathan Rodrigues Nunes: Universidade Federal do Pará, Belém, PA, Brasil.

E-mail: jonathanrodrigues58@hotmail.com

Link para o currículo Lattes: http://lattes.cnpq.br/4108256284598873

Silvia Helena Ribeiro Cruz: Universidade Federal do Pará, Belém, PA, Brasil.

E-mail: silhcruz@gmail.com

Link para o currículo Lattes: http://lattes.cnpq.br/8432421463410679

Data de submissão: 30 de agosto de 2016

Data de recebimento de correções: 05 de maio de 2017

Data do aceite: 05 de maio de 2017

Avaliado anonimamente 